\title{
P01-7-9 Poster session
}

\section{Instructing introductory pharmacology in large undergraduate classes by using clinical problem-based learning (PBL) cases improves the generic problem- solving skills of students}

\section{Andis Klegeris}

\section{Department of Biology, University of British Columbia Okanagan Campus, Canada}

After completing their studies at university, most pharmacology and pharmacy graduates will work in small-group settings with colleagues they do not choose. They will be required to independently navigate large volumes of scientific literature, searching for reliable sources of information about various drugs and clinical conditions; prioritize their tasks and hypotheses; problem solve; network and work effectively in a team environment; and evaluate the job performance of their co-workers. Although these skills are valued by the majority of science students and their potential employers, most standard university curricula are focused on delivering the course content. These standard curricula provide very few opportunities for students to work on their essential workplace skills.

A tutor-less method of problem-based learning (PBL) suitable for large undergraduate classes was developed to model the real-life aspects of the post-university workplace. PBL tutorials were used to supplement a standard lecture-based instruction in two introductory pharmacology courses at the University of British Columbia in Canada. Over a six-week period, students work in class on various clinical cases involving different pharmacological agents in randomly assigned small groups, and supplement their discussion with independent research outside the classroom.

Our pedagogical research demonstrates that this mode of instruction leads to increased student satisfaction and engagement. Using a generic problem-solving test tool that we have developed, we show that students taking the pharmacology course using large-classroom PBL demonstrate statistically significant improvement in their generic problem-solving skills. This finding contrasts the data obtained from more than twenty other upper-year undergraduate courses that used mainly lecture-based course content delivery techniques without incorporating PBL. The tool that we have developed for studies of the dynamics of the generic problem-solving skills in various student populations is available by contacting Andis.Klegeris@ubc.ca.

If these observations are confirmed in other universities, it could be concluded that most standard lecture approaches do not effectively improve problem-solving skills of students. Universities and individual instructors must take active strides to advance this critical skill set in undergraduate students. Supplementing pharmacology lecture delivery in large classes with PBL-based cases involving clinically used drugs could be one such strategy. 